\title{
Modelling health belief predictors of oral health and dental anxiety among adolescents based on the Health Belief Model: a cross-sectional study
}

\author{
Bilu Xiang ${ }^{1}$, Hai Ming Wong ${ }^{1 *}$ (D), Antonio P. Perfecto ${ }^{1}$ and Colman P. J. McGrath ${ }^{2}$
}

\begin{abstract}
Background: A vicious cycle exists between dental anxiety, oral health behaviors and oral health status. Based on previous research, psychological factors of the Health Belief Model (HBM) are associated with oral health behaviors and oral health, and are likely involved in this cycle. However, little is known about the relationship between HBM factors and dental anxiety of adolescents. The purpose of this cross-sectional study was to investigate the relationship between health belief factors, oral health and dental anxiety based on the constructs of the HBM.

Methods: 1207 Grade 2 students from 12 secondary schools in Hong Kong were randomly selected and measured for the decayed, missing and filled permanent teeth (DMFT) index. Data for oral health behaviors, HBM constructs and dental anxiety were collected using questionnaires. The hierarchical entry of explanatory variables into logistic regression models estimating prevalence odds ratios (POR) were analyzed and 95\% confidence intervals (95\% Cl) for DMFT and dental anxiety were generated. Path analysis was used to evaluate the appropriateness of the HBM as predictors for oral health behaviors, DMFT and dental anxiety.

Results: Based on the full model analysis, individuals with higher perceived susceptibility of oral diseases (POR: 1.33, 95\% Cl: 1.14-1.56) or girls or whose mother received higher education level were likelier to have a DMFT $\geq 1$, while those with higher perceived severity (POR: 1.31,95\%Cl: 1.09-1.57), flossing weekly, DMFT $\geq 1$ or higher general anxiety level statistically increases the possibility of dental anxiety. The results from path analysis indicated that stronger perceived susceptibility, greater severity of oral diseases, less performing of oral health behaviors and a higher score of DMFT were directly related to increased dental anxiety level. Other HBM variables, such as perceived susceptibility, self-efficacy beliefs, cues to action and perceived barriers, might influence dental anxiety through oral health behaviors and caries status.
\end{abstract}

Conclusions: Clarifying the propositional structures of the HBM may help the future design of theory-based interventions in reducing dental anxiety and preventing dental caries.

Keywords: Dental anxiety, Health belief model, Path analysis, Oral health behavior, Oral health, Adolescent

\footnotetext{
* Correspondence: wonghmg@hku.hk

${ }^{1}$ Department of Paediatric Dentistry, Faculty of Dentistry, The University of

Hong Kong, 2/F The Prince Philip Dental Hospital, 34 Hospital Road, Sai Ying

Pun, Hong Kong, SAR, China

Full list of author information is available at the end of the article
}

C The Author(s). 2020 Open Access This article is licensed under a Creative Commons Attribution 4.0 International License, which permits use, sharing, adaptation, distribution and reproduction in any medium or format, as long as you give appropriate credit to the original author(s) and the source, provide a link to the Creative Commons licence, and indicate if changes were made. The images or other third party material in this article are included in the article's Creative Commons licence, unless indicated otherwise in a credit line to the material. If material is not included in the article's Creative Commons licence and your intended use is not permitted by statutory regulation or exceeds the permitted use, you will need to obtain permission directly from the copyright holder. To view a copy of this licence, visit http://creativecommons.org/licenses/by/4.0/. The Creative Commons Public Domain Dedication waiver (http://creativecommons.org/publicdomain/zero/1.0/) applies to the data made available in this article, unless otherwise stated in a credit line to the data. 


\section{Background}

A vicious cycle of dental anxiety, oral health behavior and oral health status has been hypothesized [1]. The vicious cycle theory is proposed that dental anxiety plays a role in the dental avoidance pattern, which in turn, leads to untreated diseases, causing the deterioration of dental anxiety [2]. Nevertheless, findings from another study do not support this downward spiral [3]. The factors which play the major roles and/or initiate the cycle remain unclear. A 3-year cohort study has demonstrated the role of Decayed Missing Filled Teeth (DMFT) scores in the development of dental anxiety, which brings an idea to the mechanism of the vicious cycle [4]. Additionally, multifaceted socio-economical and psychosocial aspects are involved in the onset of dental anxiety [1]. Psychological factors such as personality traits or attachment patterns are also important in the development and persistence of dental anxiety [5, 6]. Children with low psychological functioning tend to have higher levels of dental anxiety and increased social problems [5]. Moreover, self-rated oral health status can trigger dental anxiety which is mediated by certain cognitive vulnerabilities, such as threat or disgust [7]. Signs of depression and anxiety in adolescents [6], as well as higher psychological distress [8], are highly correlated to dental anxiety.

Dental anxiety among youth is a common problem in dental practice. The prevalence of dental anxiety among adolescents ranges from 9.4 to $19 \%$ [9]. Almost half of the adolescents in Hong Kong have experience of caries $(\mathrm{DMFT} \geq 1)[10,11]$, which is similar to some European countries and the United States [12, 13]. Adolescence is a transitional phase from childhood to adulthood, with biological and psychological developmental changes occurring, such as social-networking [14]. In a retrospective study, $22 \%$ of respondents reported that their dental anxiety emerged in adolescence [15]. In establishing their health-related behavior and attitudes, dental avoidance in adolescents has the potential to influence their oral health in the short-term and long-term [16].

Psychosocial factors, such as "intention", "social influences", and "self-efficacy", have been identified as important modifiable determinants of tooth brushing frequencies of adolescents [17]. The Health Belief Model (HBM) is one of the psychological theories, which posits that one engages in particular health behaviors based on his belief towards susceptibility to illness and severity, and the perception that there are more benefits over barriers to taking action against illness $[18,19]$. Previous research has found that the HBM can predict tooth brushing, flossing and dental visit behaviors [20, 21]. To reinforce the predictability of the HBM, self-efficacy was added into the model to extend the original HBM and was further demonstrated as the strongest predictor of health behaviors in this model [22, 23]. Studies have demonstrated that stronger self-efficacy beliefs and greater perceived severity of oral diseases were related to increased tooth brushing frequency, which in turn was associated with better oral health status [24]. The HBM has not adequately considered the role of emotionality in performing health behaviors, since negative emotions, such as fear or sad moods, might be related to perceived susceptibility and perceived severity [23, 24]. Regarding breast cancer research, individuals with high anxiety levels were found associated with higher perceived severity scores and lower self-efficacy scores [25]. The HBM has also been applied in mental health and anxiety relief contexts [26]. Nevertheless, we are unaware of studies investigating the importance of HBM variables in oral health and dental anxiety contexts.

The objectives of the study were (a) to identify psychological factors contributing to oral health and dental anxiety based on the HBM and (b) to explore the direct and indirect associations of the HBM factors on oral health and dental anxiety via oral health behaviors among Hong Kong adolescents. To the best of our knowledge, this is the first study employing a theoretical model to explore HBM constructs involved in dental anxiety via oral health behaviors and oral health status. A well-known conceptual model of influences on healthrelated behaviors has been described by Janz and Becker et al. [27]. Based on the previous model, we hypothesized that oral health beliefs (as conceptualized by HBM) involving higher susceptibility, greater severity, more barriers, fewer perceived benefits and weaker selfefficacy, would be associated with increased dental anxiety scores directly or indirectly through oral health behaviors and oral health status.

\section{Methods}

\section{Participants and sampling}

The study was approved by the Institutional Review Board of the University of Hong Kong/Hospital Authority Hong Kong West Cluster (HKU/HA HKW IRB) (IRB HKU: UW18-029). We hypothesized the prevalence of dental anxiety in the adolescent population as $19.5 \%$ based on previous studies [9]. The percentage frequency of the estimated dental anxiety was set at $19.5 \%$ with confidence limits of $\pm 2.5 \%$ and a significant level set at $5 \%$. The sample size was calculated for 965 subjects. Accounting for an $85 \%$ response rate, 1136 subjects were required for recruitment. A list of government-funded secondary schools was retrieved from the official website of the Education Bureau, Hong Kong Special Administrative Region (http://www.edb.gov.hk). All secondary schools were coded respectively in the list of their district area (there were four districts of the Hong Kong SAR, i.e. New Territories West, New Territories East, 
Kowloon and Hong Kong Island). Three schools were randomly selected from each of the four districts using the bowl method, given that there were approximately 100 Grade 2 students in each secondary school. The inclusion criterion included every Grade 2 student from the 12 invited schools. Students with severe systemic diseases, physical, or psychological disabilities were excluded. All eligible adolescents in the participating schools were approached. Written informed consents from parents were obtained prior to their child's participation. The data were collected through self-reported questionnaires and clinical oral examinations from September 2018 to November 2018.

\section{Measures}

The questionnaire was filled by participants under the supervision of the teacher-in-charge in order to prevent student interaction and maintain data integrity. Age and the gender of participants were requested. The following oral health-related behaviors were measured: frequency of tooth brushing (1. Less than twice a day; 2 . Twice or more a day), flossing frequency (1. Never or less than once a week; 2 . Once or more a week), sugar consumption (1. Several times a week or daily; 2 . Rare) and dental visits (1. No regular dental visit; 2. Have an annual dental visit). Each beneficial behavior scored 1 while discouraged behavior scored 0 . The oral health behavior (OHB) score was calculated by summing up the scores of the four beneficial behaviors (ranged from 0 to 4 ), with a higher score indicating a higher level of oral health behavior.

The constructs of the HBM were measured using a validated questionnaire, Oral Health Behavior Questionnaire for Adolescents based on the Health Belief Model (OHBQAHBM), which consists of 35 items related to 6 interrelated components of the HBM; Perceived Susceptibility (2 items), Perceived Benefits (7 items), Perceived Barriers (6 items), Cues to Action (3 items), Perceived Severity (7 items) and Self-efficacy (10 items) [28]. Each item was scored on a scale from 1 to 5 points and the average score for each subscale was calculated thereby representing the individual's belief towards that specific component. For each subscale, a higher average score indicates a stronger feeling towards its corresponding component.

Dental anxiety was assessed using a validated questionnaire, the Modified Child Dental Anxiety Scale consisting of 8 questions [29]. Responses were scored from 1 to 5 points, giving a total score of 8-40. A higher score indicates a higher dental anxiety level. The total score was categorized into no anxiety (8-19), mild to moderate anxiety (20-25) and severe anxiety (26-40) for analysis [30]. General anxiety levels were measured using the Chinese version of the Generalized Anxiety Disorder-7
[31]. In the 7-item self-rating questionnaire, each item is scored 0-4 points, giving a total range from 0 to 28 . A higher score indicates a higher general anxiety level.

Two trained and calibrated dentists conducted dental examinations in schools using dental mirrors with added lights and Community Periodontal Index probes. Dental caries diagnosis was determined according to the criteria of WHO [32]. DMFT (number of decayed, missing, and filled teeth due to caries) score was calculated. To avoid measurement bias, the clinical examinations were performed unannounced in advance. 10\% of children from each school were randomly selected and re-examined on the same day. Acceptable intra- and inter-examiner reliability was achieved (kappa $=0.90-0.94)$.

\section{Data analysis}

The percentage of missing values of the questionnaire was $0.3-7.0 \%$. For eligible participants, an MCAR (missing completely at random) analysis in SPSS was undertaken to test whether data were missing at random. The $p$-value for the MCAR analysis were all $>0.05$, signifying that our data were missing completely at random. The expectation maximization algorithm was used to replace the missing values with predicted values.

Correlation tests confirmed weak associations among the HBM factors, oral health and dental anxiety (Spearman's Rho correlation range 0.1-0.4). Variables were not excluded due to collinearity. The comparison of DMFT and dental anxiety between different groups was assessed using chi-square test. The column proportion test was performed to identify whether the prevalence of DMFT and severe dental anxiety in that column was significantly different from other columns. Unadjusted associations between independent variables related to DMFT/ severe dental anxiety were estimated through the odds ratio (OR) and 95\% confidence interval (CI). A normality distribution test for general anxiety score, DMFT and HBM variables was used. Since the data were not normally distributed, a Mann-Whitney $U$ test was used to compare the median between groups. Blocks of explanatory variables were entered into a binary logistic regression model using a hierarchical methodology, as predicated by our conceptual model (Fig. 1). The dependent variable of these models were DMFT $\geq 1$ or DMFT $=0$ and the existence of severe dental anxiety. The HBM construct factors were entered into Model 1. The modifying factors were entered into Model 2 and oral health behaviors entered into Model 3. For DMFT, the severe dental anxiety level was entered into Model 4. The full model of DMFT (Model 5) comprised the factors in Model 1-4. For severe dental anxiety, DMFT was entered into Model 4 and general anxiety entered into Model 5. The full model of dental anxiety (Model 6) comprised all factors. It is important to note that the full 


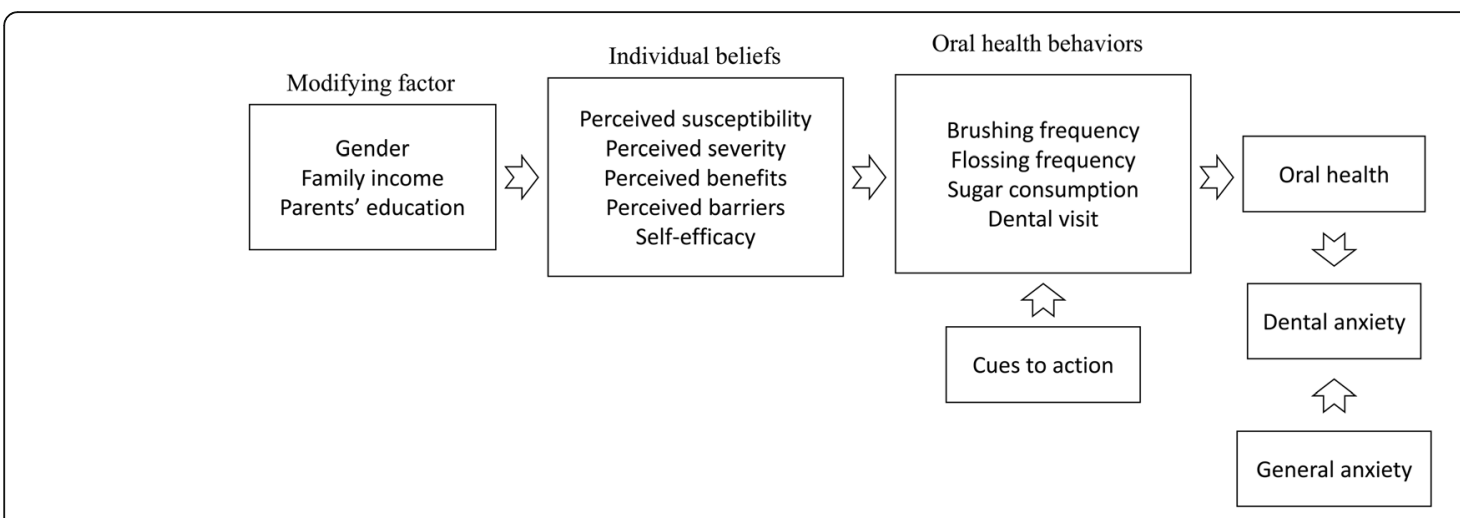

Fig. 1 Theoretical model for the study of the health belief model to predict oral health status and dental anxiety (Adapted from Janz \& Becker, 1984 [17])

model was built based on a priori selection of covariates according to the conceptual model (Fig. 1) as opposed to covariate selection based upon bivariate statistics. The degree of attenuation was calculated by the 1-[ln (adjusted OR)/ln (unadjusted OR)] formula [33]. In the regression analysis, the HBM factors were continuous variables, whereas gender, parents' education level, family income and oral health behaviors were categorical variables. The model fit of the regression model was assessed using the Hosmer-Lemeshow test [34]. A $p$ value of the Hosmer-Lemeshow test larger than 0.05 indicated a good fit. The above mentioned statistical analysis was conducted using SPSS 25.0. The chosen level of significance of all the statistical tests was $p<0.05$ (twotailed).

To explore the relationship between HBM variables, general anxiety, $\mathrm{OHB}$ and DMFT, a path analysis was performed using AMOS 22.0. All variables in the path analysis model were included as continuous variables. The univariate distributions of all variables in the theoretical path model were checked for normality and the skewness and kurtosis values were also measured. Because of the presence of non-normally distributed variables, the path model was evaluated using the Bollen-Stine bootstrapping procedure [35]. In this model, oral hygiene beliefs were posited to be related to dental anxiety both directly and indirectly through oral health behaviors and oral health status. If the $p$ value of the chi-square statistics $\left(x^{2}\right)$ exceeded 0.05 , the hypothesized path analysis was retained. The model fit was evaluated using multiple fit indices, such as the comparative fit index (CFI), goodness-offit index (GFI), Tucker-Lewis index (TLI), the root mean square error of approximation (RMSEA) and the standardized root mean squared residual (SRMR). Cut-offs to consider the model a good fit to the data were $\mathrm{CFI}>0.90, \quad$ TLI $>0.90, \quad$ RMSEA $<0.06$ and $\mathrm{SRMR}<0.08[36]$.

\section{Results}

Sample characteristics

Of the 1207 eligible participants, 1159 participated in clinical examinations and returned questionnaires (response rate $=96 \%$ ). The mean age of the participants was $14.32 \pm 0.68$ and the proportion of girls were $46.6 \%$. The prevalence of severe dental anxiety [30] among Hong Kong adolescents was $13.7 \%$. Nearly half of adolescents $(45.0 \%)$ had a DMFT $\geq 1$ (Table 1). $67.9 \%$ of adolescents brushed their teeth at least twice a day, but only 20.3\% flossed weekly. Most adolescents (81.7\%) consumed sugar every week and less than a quarter (23.3\%) had annual dental visitation plans. A high proportion of adolescents with DMFT $\geq 1$ were girls with highly educated parents who had stronger perceived susceptibility of oral diseases and more perceived barriers towards performing OHB (Table 1). Dental anxiety among participants was associated with being a girl, lower flossing rates, higher sugar consumption rates, DMFT $\geq 1$, stronger perceived susceptibility, stronger perceived severity, lower self-efficacy and higher general anxiety levels (Table 1).

The Hosmer-Lemeshow test showed a good model fit of all the logistic regression analysis. For an unadjusted model of HBM variables, every increase of one unit in perceived susceptibility resulted in 1.44 times the odds for DMFT $\geq 1$ (Table 2, Model 1). The addition of modifying factors to HBM variables attenuated the effect of perceived susceptibility on DMFT by $14 \%$ (Table 2, Model 2), while the addition of oral health behavior variables to HBM variables attenuated the odds by $8 \%$ (Table 2, Model 3). The OR was attenuated by $3 \%$ with the addition of severe dental anxiety (Table 2, Model 4). A strong perceived susceptibility persisted as a risk indicator for DMFT $\geq 1$ in the final model, which included all covariates. In the full model, the odds of perceived susceptibility was attenuated by 25\% (Table 2, Model 5). In addition, girls, low 


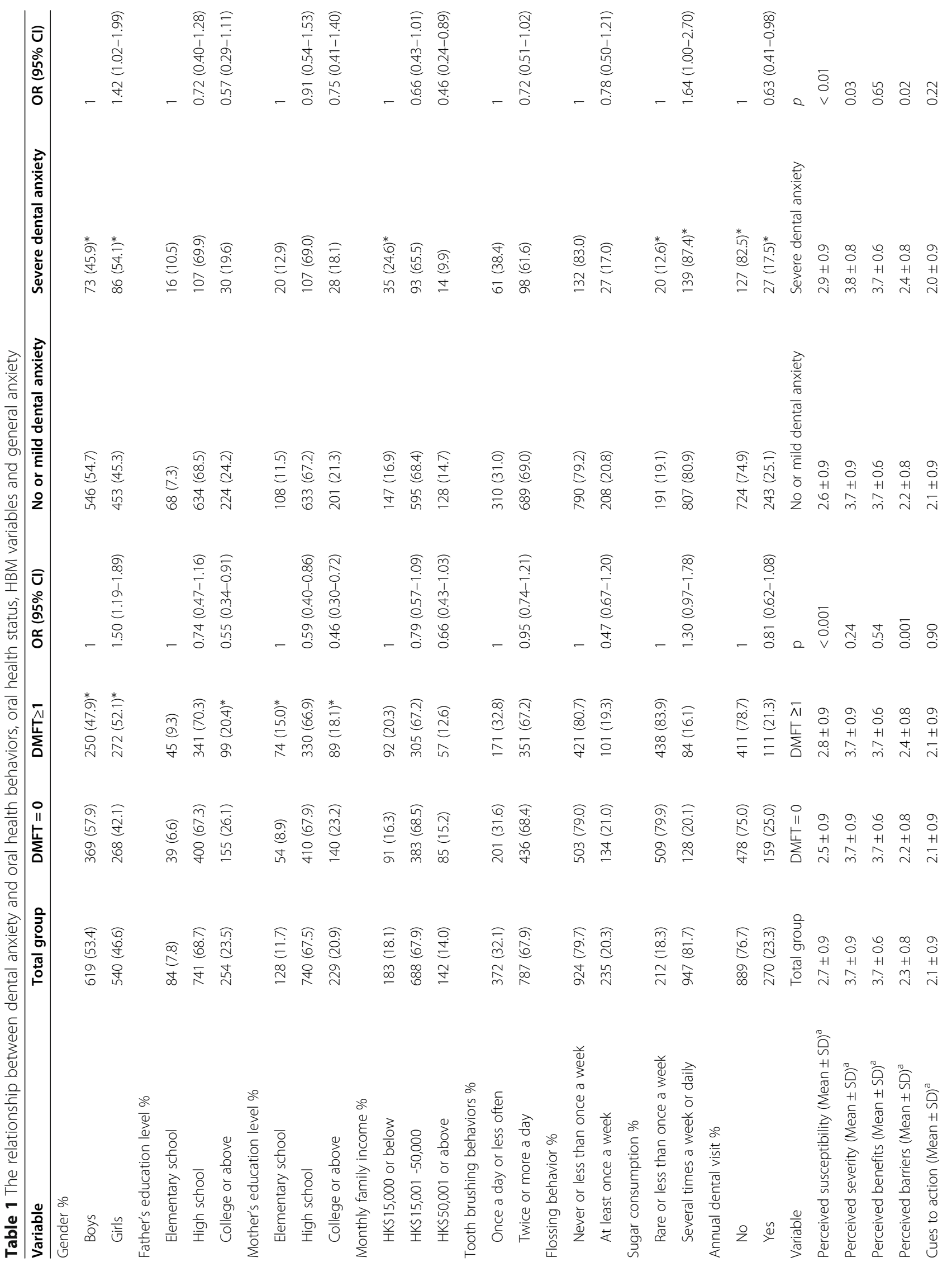




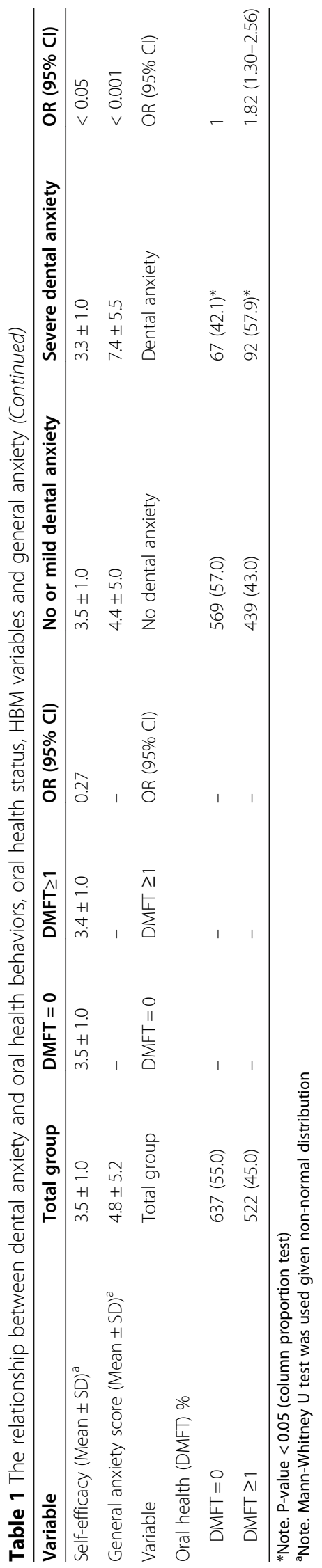


Table 2 Multivariable models evaluating risk indicators for DMFT $\geq 1$ among adolescents

\begin{tabular}{|c|c|c|c|c|c|}
\hline & Model 1 (POR, 95\% Cl) & Model 2 (POR, 95\% Cl) & Model 3 (POR, 95\% Cl) & Model 4 & $\begin{array}{l}\text { Model } 5 \\
\text { (POR, 95\% Cl) }\end{array}$ \\
\hline Perceived susceptibility & $1.44(1.25-1.65)^{*}$ & $1.36(1.16-1.59)^{*}$ & $1.39(1.21-1.61)^{*}$ & $1.42(1.24-1.63)^{*}$ & $1.31(1.12-1.54)^{*}$ \\
\hline Perceived severity & $1.00(0.87-1.15)$ & $0.94(0.80-1.11)$ & $1.01(0.87-1.16)$ & $0.98(0.85-1.14)$ & $0.92(0.78-1.09)$ \\
\hline Perceived benefits & $0.98(0.79-1.20)$ & $1.05(0.83-1.33)$ & $0.97(0.79-1.20)$ & $0.98(0.79-1.20)$ & $1.05(0.83-1.33)$ \\
\hline Perceived barriers & $1.16(0.97-1.39)$ & $1.16(0.95-1.42)$ & $1.15(0.95-1.39)$ & $1.13(0.95-1.36)$ & $1.16(0.93-1.44)$ \\
\hline Cues to action & $0.96(0.84-1.10)$ & $1.00(0.86-1.17)$ & $0.98(0.85-1.13)$ & $0.97(0.85-1.12)$ & $1.02(0.87-1.19)$ \\
\hline Self-efficacy & $1.02(0.89-1.15)$ & $1.00(0.87-1.16)$ & $1.01(0.88-1.16)$ & $1.02(0.90-1.16)$ & $1.00(0.86-1.17)$ \\
\hline \multicolumn{6}{|l|}{ Sex } \\
\hline Boy & - & 1 & - & & 1 \\
\hline Girl & - & $1.63(1.25-2.12)^{*}$ & - & & $1.64(1.24-2.17)^{*}$ \\
\hline \multicolumn{6}{|l|}{ Father's education level } \\
\hline Elementary school & - & 1 & - & & 1 \\
\hline High school & - & $0.76(0.46-1.25)$ & - & & $0.73(0.44-1.21)$ \\
\hline College or above & - & $0.66(0.37-1.21)$ & - & & $0.64(0.35-1.17)$ \\
\hline \multicolumn{6}{|l|}{ Mother's education level } \\
\hline Elementary school & - & 1 & - & & 1 \\
\hline High school & - & $0.58(0.38-0.89)^{*}$ & - & & $0.58(0.38-0.91)^{*}$ \\
\hline College or above & - & $0.56(0.32-0.98)^{*}$ & - & & $0.54(0.31-0.96)^{*}$ \\
\hline \multicolumn{6}{|l|}{ Family income per month } \\
\hline HK\$15,000 or below & - & 1 & - & & 1 \\
\hline HK\$15,001 -50,000 & - & $1.00(0.69-1.43)$ & - & & $1.02(0.71-1.49)$ \\
\hline HK\$50,001 or above & - & $1.01(0.61-1.68)$ & - & & $1.07(0.64-1.79)$ \\
\hline \multicolumn{6}{|l|}{ Tooth brushing behavior } \\
\hline Once a day or less often & - & - & 1 & & 1 \\
\hline Twice or more a day & - & - & $0.96(0.73-1.28)$ & & $0.94(0.68-1.30)$ \\
\hline \multicolumn{6}{|l|}{ Flossing behavior } \\
\hline Never or less than once a week & - & - & 1 & & 1 \\
\hline At least once a week & - & - & $0.99(0.73-1.35)$ & & $1.01(0.71-1.42)$ \\
\hline \multicolumn{6}{|l|}{ Sugar consumption } \\
\hline Rare or less than once a week & - & - & 1 & & 1 \\
\hline Several times a week or daily & - & - & $1.23(0.69-1.26)$ & & $1.09(0.75-1.57)$ \\
\hline \multicolumn{6}{|l|}{ Annual dental visit } \\
\hline No & - & - & 1 & & $1.08(0.76-1.53)$ \\
\hline Yes & - & - & $0.93(0.69-1.26)$ & & \\
\hline \multicolumn{6}{|l|}{ Dental anxiety level } \\
\hline No or mild & & & & 1 & 1 \\
\hline Severe & & & & $1.66(1.17-2.35)^{*}$ & $1.51(1.03-2.21)^{*}$ \\
\hline-2 Log likelihood & 1558 & 1261 & 1508 & 1549 & 1218 \\
\hline Nagelkerke $R^{2}$ & 0.042 & 0.072 & 0.042 & 0.051 & 0.080 \\
\hline
\end{tabular}

Note: ${ }^{*} \mathrm{p}<0.05$

education level of mothers and having severe dental anxiety were also significantly associated with DMFT $\geq 1$ in the full model (Table 2, Model 5).

In the unadjusted model, the increase in perceived susceptibility, perceived severity, perceived barriers and significantly resulted in a higher chance of severe dental anxiety (Table 3 , Model 1 ). In the full model, only perceived susceptibility and perceived severity remained significantly associated with severe dental anxiety. The odds of perceived susceptibility and perceived severity 
on severe dental anxiety were 1.27 and 1.38 , which were attenuated by $11 \%$ and intensified by $10 \%$ after adjusting for confounding factors, respectively (Table 3, Model 6). In addition, tooth brushing behavior, DMFT and general anxiety remained statistically associated with severe dental anxiety in the full model (Table 3, Model 6).

\section{Path analysis modeling}

The model was firstly based on the conceptual model and secondly modified according to the regression results. Three paths were added to the model: one path between perceived susceptibility and dental anxiety; and one path between perceived severity and dental anxiety; furthermore, one path linked the perceived susceptibility to oral health (DMFT). The final model is depicted in Fig. 2 and Table 4. The model was well fitted (TLI = 0.99; $\mathrm{CFI}=1.00 ; \mathrm{RMSEA}=0.01 ; \mathrm{SRMR}=0.01$; BollenStine bootstrap $p=0.35$ ). Regarding the direct effect, a significant path was noted from general anxiety to dental anxiety $(\beta=0.44, p<0.01)$. Consistent with the regression results, higher perceived susceptibility $(\beta=0.56, p=$ $0.03)$ and greater perceived severity $(\beta=0.72, \mathrm{p}<0.01)$ were associated with greater dental anxiety. Significant direct paths were also found to OHB from perceived susceptibility ( $\beta=-0.07, p=0.04)$, self-efficacy $(\beta=0.20$, $\mathrm{p}<0.01)$, perceived barriers $(\beta=-0.25, \mathrm{p}<0.01)$ and cues to action $(\beta=0.08, p=0.01)$. Regarding the direct effects of OHB and DMFT on dental anxiety, both were significant $(\beta=-0.74, \mathrm{p}<0.01 ; \beta=0.28, p=0.02)$.

For indirect effects exerted through OHB and DMFT, perceived susceptibility $(\beta=0.14, p<0.01)$, self-efficacy beliefs $(\beta=-0.16, p<0.01)$, cues to action $(\beta=-0.06$, $\mathrm{p}<0.01)$ and perceived barriers $(\beta=0.19, \mathrm{p}<0.01)$ were statistically significant. The dotted line of Fig. 2 denoted the insignificant paths, but for conceptual reasons, it was decided to retain the paths. The final model explained $14 \%$ of variances in oral health behaviors and $14 \%$ of variances in dental anxiety.

\section{Discussion}

This study suggests that HBM factors are risk indicators for caries and dental anxiety among Hong Kong adolescents. After adjusting for socio-demographic factors and behavior covariates, the association of perceived susceptibility with DMFT score and perceived severity in relation to dental anxiety was maintained.

We believe that this is the first study to examine the complex predictors regarding oral health and dental anxiety after accounting for the impact of HBM variables in a path analysis model of data. Our findings suggested that perceived susceptibility, perceived barriers, selfefficacy and cues to action could predict oral health behaviors. The results were in accordance with other studies that perceived barriers, self-efficacy and cues to action played a role in predicting oral health behaviors $[37,38]$. Perceived benefit was rarely identified as a significant predictor. Some research also did not support the predictability of perceived severity to behavior change $[37,39]$. The reason why the perceived severity was not identified as a predictor might be the adoption of perceived subjective severity in the present study. Perceived severity contained two distinct concepts: subjective severity and objective severity; objective severity played a more important role in predicting oral health behaviors among young adolescents rather than subjective severity [40]. Besides, our study indicated that selfefficacy and perceived barriers were the strongest predictors of oral health behaviors, which confirmed the results from other studies [37, 41, 42]. It was even claimed in a study that reducing barriers was one of the most useful strategies to encourage oral health behaviors [37].

What's more, our findings suggested that oral health beliefs (including HBM constructs) were associated with dental anxiety directly or indirectly via $\mathrm{OHB}$ and oral health. In recent decades, pressure has been placed on therapeutics to reduce patients' anxiety in the long term without pharmacological use $[43,44]$. Psychological treatments have displayed better improvement in dental anxiety prevention in the long term compared to the use of pharmaceuticals [45]. In our study, we identified the role of HBM psychological constructs on the severity of dental anxiety. Threat-related perceptions based on past experiences may bring negative expectations of dental treatment and trigger dental phobia [46]. From the perspective of the HBM, threat perceptions are based on two beliefs: perceived susceptibility and perceived severity [23]. Perceived susceptibility refers to the chance of obtaining a disease or a painful state; perceived severity refers to one's belief towards the effect and psychological harm the disease could create [23]. In previous research on preoperative anxiety, perceived severity was a risk factor for increased anxiety levels [47]. Moreover, negative emotions, such as fear and sadness, was found to have a link with the perceived threat [24, 48]. One study proposed a mechanism that the rehearsal of threatening outcomes in the absence of active planning or activation of relevant coping information increased anxious arousal [49]. As proposed by the extended parallel process model, fear, as well as anxiety, were aroused by threatrelated emotions, including perceived susceptibility and perceived severity, and those two threat messages played a role in protection intention against diseases [50]. In the present study, perceived severity and perceived susceptibility were positively correlated with dental anxiety directly, whereas perceived susceptibility showed a positive, though nonsignificant direct effect on oral health. These results were consistent with a study on meningitis, in which the perceived susceptibility was the most 
Table 3 Multivariable models evaluating risk indicators for severe dental anxiety among adolescents

\begin{tabular}{|c|c|c|c|c|c|c|}
\hline & $\begin{array}{l}\text { Model } 1 \text { (POR, } \\
95 \% \mathrm{Cl})\end{array}$ & $\begin{array}{l}\text { Model } 2 \text { (POR, } \\
95 \% \mathrm{Cl})\end{array}$ & $\begin{array}{l}\text { Model } 3 \text { (POR, } \\
95 \% \mathrm{Cl})\end{array}$ & $\begin{array}{l}\text { Model } 4 \text { (POR, } \\
95 \% \mathrm{Cl})\end{array}$ & $\begin{array}{l}\text { Model } 5 \text { (POR, } \\
95 \% \mathrm{Cl})\end{array}$ & $\begin{array}{l}\text { Model } 6 \text { (POR, } \\
95 \% \mathrm{Cl})\end{array}$ \\
\hline Perceived susceptibility & $1.31(1.07-1.59)^{*}$ & $1.38(1.11-1.72)^{*}$ & $1.27(1.04-1.56)^{*}$ & $1.25(1.02-1.53)^{*}$ & $1.26(1.03-1.54)^{*}$ & $1.27(1.01-1.60)^{*}$ \\
\hline Perceived severity & $1.34(1.08-1.66)^{*}$ & $1.40(1.09-1.78)^{*}$ & $1.39(1.11-1.73)^{*}$ & $1.35(1.08-1.68)^{*}$ & $1.25(1.00-1.56)^{*}$ & $1.38(1.07-1.78)^{*}$ \\
\hline Perceived benefits & $1.02(0.76-1.37)$ & $1.00(0.73-1.38)$ & $0.97(0.72-1.32)$ & $1.02(0.75-1.37)$ & $1.01(0.74-1.37)$ & $0.93(0.66-1.30)$ \\
\hline Perceived barriers & $1.36(1.06-1.73)^{*}$ & $1.29(0.98-1.70)$ & $1.30(0.99-1.70)$ & $1.34(1.04-1.71)^{*}$ & $1.33(1.04-1.71)^{*}$ & $1.17(0.86-1.59)$ \\
\hline Cues to action & $0.85(0.70-1.05)$ & $0.92(0.74-1.15)$ & $0.89(0.72-1.10)$ & $0.86(0.70-1.05)$ & $0.88(0.72-1.09)$ & $0.97(0.77-1.22)$ \\
\hline Self-efficacy & $0.89(0.74-1.06)$ & $0.88(0.72-1.08)$ & $0.95(0.77-1.16)$ & $0.89(0.74-1.06)$ & $0.95(0.79-1.14)$ & $1.06(0.84-1.33)$ \\
\hline \multicolumn{7}{|l|}{ Sex } \\
\hline Boy & - & 1 & - & - & - & 1 \\
\hline Girl & - & $1.30(0.89-1.89)$ & - & - & - & $1.14(0.76-1.70)$ \\
\hline \multicolumn{7}{|l|}{ Father's education level } \\
\hline Elementary school & - & 1 & - & - & - & 1 \\
\hline High school & - & $0.79(0.42-1.50)$ & - & - & - & $0.87(0.45-1.68)$ \\
\hline College or above & - & $0.76(0.34-1.69)$ & - & - & - & $0.80(0.35-1.81)$ \\
\hline \multicolumn{7}{|l|}{ Mother's education level } \\
\hline Elementary school & - & 1 & - & - & - & 1 \\
\hline High school & - & $1.36(0.75-2.48)$ & - & - & - & $1.50(0.80-2.80)$ \\
\hline College or above & - & $1.30(0.58-2.87)$ & - & - & - & $1.75(0.77-4.01)$ \\
\hline \multicolumn{7}{|l|}{ Family income per month } \\
\hline HK\$15,000 or below & - & 1 & - & - & - & 1 \\
\hline HK\$15,001 -50,000 & - & $1.09(0.76-1.57)$ & - & - & - & $0.76(0.47-1.22)$ \\
\hline HK\$50,001 or above & - & $1.02(0.62-1.70)$ & - & - & - & $0.51(0.24-1.09)$ \\
\hline \multicolumn{7}{|l|}{ Tooth brushing behavior } \\
\hline Once a day or less often & - & - & 1 & - & - & 1 \\
\hline Twice or more a day & - & - & $0.76(0.51-1.13)$ & - & - & $0.63(0.40-0.99)^{*}$ \\
\hline \multicolumn{7}{|l|}{ Flossing behavior } \\
\hline $\begin{array}{l}\text { Never or less than once } \\
\text { a week }\end{array}$ & - & - & 1 & - & - & 1 \\
\hline At least once a week & - & - & $0.97(0.62-1.54)$ & - & - & $0.97(0.58-1.61)$ \\
\hline \multicolumn{7}{|l|}{ Sugar consumption } \\
\hline $\begin{array}{l}\text { Rare or less than once a } \\
\text { week }\end{array}$ & - & - & 1 & - & - & 1 \\
\hline $\begin{array}{l}\text { Several times a week or } \\
\text { daily }\end{array}$ & - & - & $1.64(0.98-2.75)$ & - & - & $1.53(0.86-2.74)$ \\
\hline \multicolumn{7}{|l|}{ Annual dental visit } \\
\hline No & - & - & 1 & - & - & 1 \\
\hline Yes & - & - & $0.77(0.48-1.23)$ & - & - & $0.76(0.44-1.29)$ \\
\hline \multicolumn{7}{|l|}{ Oral health } \\
\hline $\mathrm{DMFT}=0$ & - & - & - & 1 & - & 1 \\
\hline DMFT $\geq 1$ & - & - & - & $1.66(1.17-2.35)^{*}$ & - & $1.58(1.07-2.35)^{*}$ \\
\hline General anxiety & - & - & - & - & $1.09(1.06-1.12)^{*}$ & $1.07(1.04-1.11)^{*}$ \\
\hline-2 Log likelihood & 899 & 757 & 864 & 890 & 1441 & 1151 \\
\hline Nagelkerke $\mathrm{R}^{2}$ & 0.043 & 0.065 & 0.053 & 0.056 & 0.090 & 0.113 \\
\hline
\end{tabular}

Note: ${ }^{*}<0.05$ 


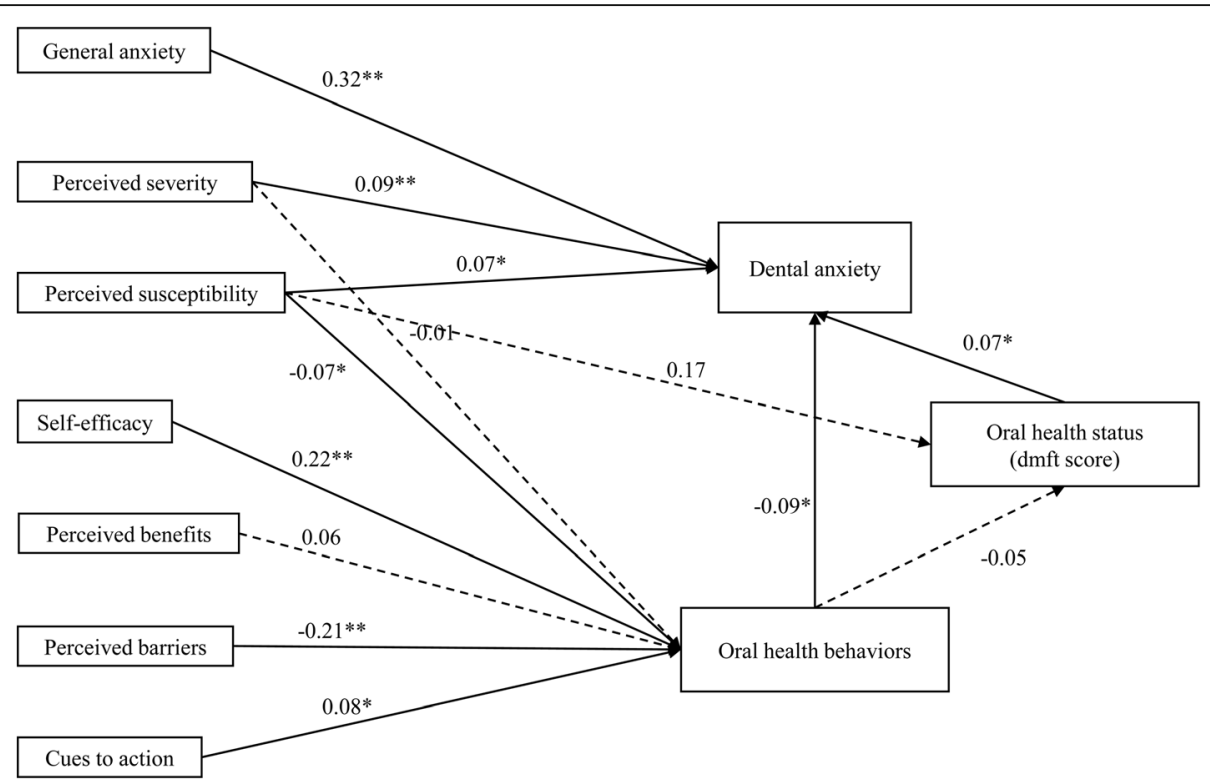

Fig. 2 Path analysis of psychological factors as predictors for dental anxiety. Standardized direct path coefficients are presented. Note. Significant differences indicated by $* * p<0.01 ; * p<0.05$

influential predictor of protective action while perceived severity contributed to a weaker effect [39]. Other variables from the HBM are able to predict dental anxiety via the oral health behavior path. The HBM theory also proposes that if an individual has sufficient self-efficacy, perceived benefits over barriers, and cues to action, he is more likely to perform a behavior [23]. Dental anxiety is a risk factor for caries in children [33] and individuals with poorer oral health practices are correlated with higher dental anxiety levels [51]. Our study results were consistent with previous studies and the HBM variables indicate that they are related to dental anxiety via $\mathrm{OHB}$ and caries status.

However, the HBM variables predicted only $14 \%$ of the variance in both oral health behaviors and dental anxiety, leaving $86 \%$ of the variance unaccounted for. This suggested that HBM factors owned the ability to predict dental anxiety as well as oral health behaviors.

Table 4 Standardized and unstandardized path coefficients of the path analysis model

\begin{tabular}{|c|c|c|c|c|c|c|}
\hline Effects & Standardized path coefficient $(\beta)$ & Unstandardized path coefficient & SE & $95 \% \mathrm{Cl}$ & Bootstrapping $p$ & $\mathrm{R}^{2}$ \\
\hline \multicolumn{7}{|l|}{ Oral health behaviors } \\
\hline Perceived susceptibility & -0.07 & -0.07 & 0.03 & -0.12 to -0.00 & 0.04 & 0.14 \\
\hline Perceived severity & -0.01 & -0.01 & 0.03 & -0.08 to 0.05 & 0.72 & \\
\hline Perceived benefits & 0.06 & 0.09 & 0.05 & -0.01 to 0.17 & 0.08 & \\
\hline Perceived barriers & -0.21 & -0.25 & 0.04 & -0.33 to -0.17 & $<0.01$ & \\
\hline Cues to action & 0.08 & 0.08 & 0.03 & 0.02 to 0.13 & 0.01 & \\
\hline Self-efficacy & 0.23 & 0.20 & 0.03 & 0.15 to 0.25 & $<0.01$ & \\
\hline \multicolumn{7}{|l|}{ Oral health (DMFT) } \\
\hline Oral health behaviors & -0.05 & -0.08 & 0.06 & -0.20 to 0.04 & 0.09 & 0.04 \\
\hline Perceived susceptibility & 0.17 & 0.30 & 0.18 & -0.06 to 0.66 & 0.16 & \\
\hline \multicolumn{7}{|l|}{ Dental anxiety } \\
\hline Perceived susceptibility & 0.07 & 0.56 & 0.24 & 0.05 to 1.03 & 0.03 & 0.14 \\
\hline Perceived severity & 0.09 & 0.72 & 0.23 & 0.31 to 1.18 & $<0.01$ & \\
\hline General anxiety & 0.32 & 0.44 & 0.04 & 0.36 to 0.52 & $<0.01$ & \\
\hline Oral health (DMFT) & 0.07 & 0.28 & 0.13 & 0.04 to 0.54 & 0.02 & \\
\hline Oral health behaviors & -0.09 & -0.74 & 0.23 & -1.18 to -0.30 & $<0.01$ & \\
\hline
\end{tabular}


But it also indicated that there are other important determinants of healthy behaviors and dental anxiety not yet accounted for by HBM. This points to the need to investigate other determinants that were not accounted for by HBM, such as demographic variables. In addition, most HBM researchers assumed that the individual determinants were only directly related to healthy behaviors and no indirect or mediating effects exist between the variables [23]. Finally, based on the amount of variance that HBM contributed to oral health behaviors and dental anxiety, it would be beneficial to investigate whether the HBM-based strategy is effective in clinical trials in future studies.

\section{Limitations}

One of the major limitations of our study is the crosssectional study design of the work. Given the nature of the design, a causal relationship between psychological factors and dental anxiety cannot be determined. Thus, future work is necessary to test this relationship using a longitudinal study design. Another limitation of our study is the use of self-reported measures to assess oral health behaviors. There is a possibility that social desirability may introduce bias. The third limitation of our findings is that it may not be generalizable to older adolescents as differences in psychological and physical status exist between early adolescents and late adolescents [52]. Regardless, the importance of the HBM in oral health and disease should be investigated further.

\section{Conclusions}

The present study suggests directions and further steps to be taken to reduce dental anxiety and improve oral health status in adolescents. The need for cognitivebehavioral interventions is further evidenced by the fact that $2 / 3$ of adolescents brushed their teeth as recommended (at least twice a day) but only $20.0 \%$ of adolescents flossed weekly. Most adolescents had a high frequency of sugar intakes and did not have plans for annual dental visitation. Moreover, our study found a relatively high prevalence of dental anxiety (40.5\%) and DMFT $\geq 1$ (45.0\%). A high prevalence of dental anxiety has been shown to result in increased dental avoidance and poorer oral health outcomes. Our analysis of dental anxiety and oral health from a cognitive theory model perspective, such as the HBM, provides a clearer explanation for one of the mechanisms involved in oral health and dental anxiety among adolescents. Thus, there is a tangible application for the implementation of theorybased behavioral interventions targetting the promotion of oral health behaviors in schools as an alternative strategy in reducing dental anxiety and prevent oral diseases in adolescents.

\section{Supplementary Information}

Supplementary information accompanies this paper at https://doi.org/10. 1186/s12889-020-09784-1.

Additional file 1. Questionnaire.

\section{Abbreviations}

HBM: Health Belief Model; DMFT: Missing and filled permanent teeth; POR: Prevalence odds ratios; Cl: Confidence interval; OHB: Oral health behavior; CFI: Comparative fit index; GFI: Goodness-of-fit index; TLI: TuckerLewis index; RMSEA: The root mean square error of approximation; SRMR: The standardized root mean squared residual

\section{Acknowledgments}

The author would like to thank all the participating adolescents.

\section{Authors' contributions}

BX: data collection, data analysis and writing of the manuscript. HMW: design of the study and revision of the manuscript. APP: critical review of the data analysis and results. CPJM: critical review of the manuscript. All the authors read and approved the final manuscript.

\section{Funding}

The study was financially funded by grants from the Research Grants Council of the Hong Kong Special Administrative Region, China (Project No. 17115916). The funding body has not influenced the study design, collection, analysis and interpretation of data, or how the manuscript was written.

\section{Availability of data and materials}

The datasets used and/or analyzed for the current study are available from the corresponding author on reasonable request.

\section{Ethics approval and consent to participate}

The study was approved by the Institutional Review Board of the University of Hong Kong/Hospital Authority Hong Kong West Cluster (HKU/HA HKW IRB) (IRB HKU: UW18-029). The mean age of the participants was $14.32 \pm$ 0.68 . Written informed consent from parents were obtained prior to their child's participation.

\section{Consent for publication}

Not applicable.

\section{Competing interests}

The authors declare that they have no competing interests.

\section{Author details}

'Department of Paediatric Dentistry, Faculty of Dentistry, The University of Hong Kong, 2/F The Prince Philip Dental Hospital, 34 Hospital Road, Sai Ying Pun, Hong Kong, SAR, China. '2Department of Dental Public Health, Faculty of Dentistry, The University of Hong Kong, Hong Kong, SAR, China.

Received: 25 May 2020 Accepted: 28 October 2020

Published online: 23 November 2020

\section{References}

1. Armfield JM, Stewart JF, Spencer AJ. The vicious cycle of dental fear: exploring the interplay between oral health, service utilization and dental fear. BMC Oral Health. 2007;7:1.

2. Bouma J, Uitenbroek D, Westert G, Schaub RM, van de Poel F. Pathways to full mouth extraction. Community Dent Oral Epidemiol. 1987;15(6):301-5.

3. Coxon JD, Hosey MT, Newton JT. How does dental anxiety affect the oral health of adolescents? A regression analysis of the child dental health survey 2013. Br Dent J. 2019;227(9):823-8.

4. Thomson W, Poulton R, Kruger E, Davies S, Brown R, Silva P. Changes in selfreported dental anxiety in New Zealand adolescents from ages 15 to 18 years. J Dent Res. 1997;76(6):1287-91.

5. Versloot J, Veerkamp J, Hoogstraten J. Dental anxiety and psychological functioning in children: its relationship with behaviour during treatment. Eur Arch Paediatr Dent. 2008;9(suppl 1):36-40. 
6. Wong HM, Zhang YY, Perfecto A, McGrath CPJ. Dental fear association between mothers and adolescents - a longitudinal study. PeerJ. 2020;8: e9154.

7. Carrillo-Díaz M, Crego A, Armfield JM, Romero M. Self-assessed oral health, cognitive vulnerability and dental anxiety in children: testing a mediational model. Community Dent Oral Epidemiol. 2012;40(1):8-16.

8. Abrahamsson KH, Berggren U, Carlsson SG. Psychosocial aspects of dental and general fears in dental phobic patients. Acta Odontol Scand. 2000;58(1): 37-43.

9. Klingberg G, Broberg AG. Dental fear/anxiety and dental behaviour management problems in children and adolescents: a review of prevalence and concomitant psychological factors. Int J Paediatr Dent. 2007;17(6):391406.

10. Sun L, Wong HM, McGrath CPJ. The factors that influence oral healthrelated quality of life in 15-year-old children. Health Qual Life Outcomes. 2018;16:19.

11. Li L-W, Wong HM, McGrath CP. Longitudinal association between obesity and dental caries in adolescents. J Pediatr. 2017;189:149-54.

12. Pontigo-Loyola AP, Medina-Solis CE, Borges-Yañez SA, Patiño-Marín N, IslasMárquez A, Maupome G. Prevalence and severity of dental caries in adolescents aged 12 and 15 living in communities with various fluoride concentrations. J Public Health Dent. 2007;67(1):8-13.

13. Centers for Disease Control and Prevention. Oral Health Surveillance Report: Trends in Dental Caries and Sealants, Tooth Retention, and Edentulism, United States, 1999-2004 to 2011-2016. Atlanta, GA: centers for disease control and prevention, US Dept of Health and Human Services; 2019.

14. Blakemore SJ, Mills KL. Is adolescence a sensitive period for sociocultural processing? Annu Rev Psychol. 2014;65:187-207.

15. Locker D, Liddell A, Dempster L, Shapiro D. Age of onset of dental anxiety. J Dent Res. 1999;78(3):790-6.

16. Sawyer SM, Afifi RA, Bearinger LH, Blakemore SJ, Dick B, Ezeh AC, et al. Adolescence: a foundation for future health. Lancet. 2012;379(9826): 1630-40.

17. Scheerman JF, van Loveren C, van Meijel B, Dusseldorp E, Wartewig E, Verrips $\mathrm{GH}$, et al. Psychosocial correlates of oral hygiene behaviour in people aged 9 to 19-a systematic review with meta-analysis. Community Dent Oral Epidemiol. 2016;44(4):331-41.

18. Green EC, Murphy E. Health belief model. The Wiley Blackwell Encyclopedia of health, illness, behavior, and society. New York: Wiley; 2014. p. 766-9.

19. Rosenstock IM. Why People Use Health Services. Milbank Q. 2005;83(4). https://doi.org/10.1111/j.1468-0009.2005.00425.x.

20. Kasmaei P, Shokravi FA, Hidarnia A, Hajizadeh E, Atrkar-Roushan Z, Shirazi KK, et al. Brushing behavior among young adolescents: does perceived severity matter. BMC Public Health. 2014;14:8.

21. Lee $C Y$, Ting CC, Wu JH, Lee KT, Chen HS, Chang YY. Dental visiting behaviours among primary schoolchildren: application of the health belief model. Int J Dent Hyg. 2018;16(2):e88-95.

22. Rosenstock IM, Strecher VJ, Becker MH. Social learning theory and the health belief model. Health Educ Quart. 1988;15(2):175-83.

23. Orji R, Vassileva J, Mandryk R. Towards an effective health interventions design: an extension of the health belief model. Online J Public Health Inform. 2012;4(3):ojphi.v4i3.4321.

24. Mitchell MM. Risk, threat, and information seeking about genital herpes: the effects of mood and message framing. Commun Stud. 2001;52(2):141-52.

25. Meryem A, Esra MK, Merve YA, Mehmet A. Gizemn, Ali MK, Kaan S. evaluation of the relationship between health belief of breast cancer screening and health anxiety; a cross-sectional study. Med Sci. 2018;8(2):1-8.

26. Langley EL, Wootton BM, Grieve R. The utility of the health belief model variables in predicting help-seeking intention for anxiety disorders. Aust Psychol. 2018;53:291-301.

27. Janz N, Becker MH. The health belief model: a decade later. Health Educ O. 1984;11(1):1-47.

28. Xiang B, Wong HM, Cao W, Perfecto AP, McGrath CP. Development and validation of the Oral health behavior questionnaire for adolescents based on the health belief model (OHBQAHBM). BMC Public Health. 2020;20:701.

29. Wong HM, Humphris GM, Lee GT. Preliminary validation and reliability of the modified child dental anxiety scale. Psychol Rep. 1998:83(suppl 3):1179-86.

30. Paryab M, Hosseinbor M. Dental anxiety and behavioral problems: a study of prevalence and related factors among a group of Iranian children aged 6-12. J Indian Soc Ped Prev Dent. 2013;31(2):82-6.
31. Tong X, An D, McGonigal A, Park SP, Zhou D. Validation of the generalized anxiety Disorder-7 (GAD-7) among Chinese people with epilepsy. Epilepsy Res. 2016;120:31-6.

32. World Health Organization. Oral health surveys: basic methods. 4th ed. Geneva: WHO; 1997

33. Wong HM, Peng SM, Perfecto AP, McGrath CPJ. Association between dental anxiety and caries experience from late childhood through adolescence to early adulthood. Commun Dent Oral Epidemiol. 2020. https://doi.org/10. 1111/cdoe.12563.

34. Hosmer DW, Lemesbow S. Goodness of fit tests for the multiple logistic regression model. Commun Stat Theory Methods. 1980;9(10):1043-69.

35. Kim H, Millsap R. Using the Bollen-Stine bootstrapping method for evaluating approximate fit indices. Multivariate Behav Res. 2014;49(6):581-96.

36. Hu LT, Bentler PM. Cut-off criteria for fit indexes in covariance structure analysis: conventional criteria versus new alternatives. Struct Equ Model Multidiscip J. 1999;6(1):1-55.

37. Buglar ME, White KM, Robinson NG. The role of self-efficacy in dental patients' brushing and flossing: testing an extended health belief model. Patient Educ Couns. 2010;78(2):269-72.

38. Rahmati-Najarkolaei F, Rahnama P, Fesharaki MG, Behnood V. Predictors of oral health behaviors in female students: an application of the health belief model. Iran Red Crescent Med J. 2016;18(11):e24747.

39. So J, Kuang K, Cho H. Reexamining fear appeal models from cognitive appraisal theory and functional emotion theory perspectives. Commun Monogr. 2016;83(1):120-44.

40. Kasmaei P, Shokravi FA, Hidarnia A, Hajizadeh E, Atrkar-Roushan Z, Shirazi KK. A. Brushing behavior among young adolescents: does perceived severity matter. BMC Public Health. 2014;14(1):8.

41. Anagnostopoulos F, Buchanan H, Frousiounioti S, Niakas D, Potamianos G. Self-efficacy and oral hygiene beliefs about toothbrushing in dental patients: a model-guided study. Behav Med. 2011;37(4):132-9.

42. Sharma M, Romas JA. Theoretical foundations of health education and health promotion. 2nd ed. Sudbury: Jones \& Bartlett; 2012.

43. Bankole O, Aderinokun G, Denloye O, Jeboda S. Maternal and child's anxiety-effect on child's behaviour at dental appointments and treatments. Afr J Med Med Sci. 2002;31(4):349-52.

44. Wong HM, Mak CM, To WM. Development of a dental anxiety provoking scale: a pilot study in Hong Kong. J Dent Sciences. 2015;10(3):240-7.

45. Thom A, Sartory G, Jöhren P. Comparison between one-session psychological treatment and benzodiazepine in dental phobia. J Consult Clin Psychol. 2000;68(3):378-87.

46. Wong HM, Mak CM, Xu YF. A four-part setting on examining the anxietyprovoking capacity of the sound of dental equipment. Noise Health. 2011 13(55):385-91.

47. Kacel EL, Morgan LS, Pereira DB. The relationship between perceived severity of stressful life events and preoperative anxiety in women undergoing surgery for suspected endometrial malignancy. J Clin Oncol. 2014;32(suppl 15):e20563.

48. Yuen KF, Li KX, Ma F, Wang X. The effect of emotional appeal on seafarers' safety behaviour: An extended health belief model. J Transp Health. 2020;16: 100810.

49. Stapinski LA, Abbott MJ, Rapee RM. Evaluating the cognitive avoidance model of generalised anxiety disorder: impact of worry on threat appraisal, perceived control and anxious arousal. Behav Res Ther. 2010;48(10):1032-40.

50. So J. A further extension of the extended parallel process model (E-EPPM): implications of cognitive appraisal theory of emotion and dispositional coping style. Health Commun. 2013;28(1):72-83.

51. DeDonnoa MA. Dental anxiety, dental visits and oral hygiene practices. Oral Hlth Prev Dent. 2012:10(2):129-33.

52. Petersen $A C$, Leffert $N$. Developmental issues influencing guidelines for adolescent health research: a review. J Adolesc Health. 1995;17(5):298-305.

\section{Publisher's Note}

Springer Nature remains neutral with regard to jurisdictional claims in published maps and institutional affiliations. 